\title{
Chemotherapy for Metastatic Breast Cancer - An Anachronism in the Era of Personalised and Targeted Oncological Therapy?
}

\section{Chemotherapie des metastasierten Mammakarzinoms - ein Anachronismus in der Ära der personalisierten zielgerichteten onkologischen Therapie?}

Authors

Affiliations
A. Schneeweiss ${ }^{1}$, E. Ruckhäberle ${ }^{2}$, J. Huober ${ }^{3}$

${ }^{1}$ Nationales Centrum für Tumorerkrankungen, Universitätsklinikum Heidelberg, Heidelberg

2 Frauenklinik, Universitätsklinikum Düsseldorf, Düsseldorf

${ }^{3}$ Brustzentrum und Gynäkologisches Krebszentrum, Universitätsfrauenklinik Ulm, Ulm

\author{
Key words \\ - metastatic breast cancer \\ - HER2-positive \\ - HER2-negative \\ - targeted therapy \\ - chemotherapy

\section{Schlüsselwörter} \\ - metastasiertes \\ Mammakarzinom \\ - HER2-positiv \\ - HER2-negativ \\ - zielgerichtete Therapie \\ - Chemotherapie
}

Deutschsprachige Zusatzinformationen online abrufbar unter: www.thieme-connect.de/ ejournals/toc/gebfra $\begin{array}{ll}\text { received } & 2.2 .2015 \\ \text { revised } & 29.4 .2015 \\ \text { accepted } & 29.4 .2015\end{array}$

Bibliography

Dol http://dx.doi.org/

10.1055/s-0035-1546150

Geburtsh Frauenheilk 2015; 75:

574-583 @ Georg Thieme

Verlag KG Stuttgart · New York .

ISSN 0016-5751

\section{Correspondence}

Prof. Dr. med.

Andreas Schneeweiss

Nationales Centrum

für Tumorerkrankungen

Universitäts-Klinikum

Heidelberg

Im Neuenheimer Feld 460

69120 Heidelberg

andreas.schneeweiss@

med.uni-heidelberg.de

\section{Abstract \\ $\nabla$}

Based on the findings of modern molecular biology, breast cancer is nowadays considered to be a heterogeneous disease. This leads to the objective of an individualised, more patient-oriented therapy. A series of target molecules for this purpose has already been identified. The principle of targeted oncological therapy was realised decades ago with the introduction of endocrine therapy for patients with hormone receptor-positive tumours. The modern therapy for HER2-positive tumours is a further example for the translation of targeted therapy into clinical routine. For patients with HER2-negative metastatic breast cancer, to date two targeted drugs, bevacizumab and everolimus, are available for routine clinical use. Many other substances are still undergoing clinical development. However, validated predictive markers to aid in therapeutic decision-making and therapy control are still lacking. Chemotherapy constitutes an effective palliative therapy with proven efficacy for the patients. In this process strategies have also been realised for a targeted therapy against tumour cells with the help of chemotherapeutic agents such as, for example, the intracellular activation of the prodrug capecitabine or the active albumin-mediated transport of nab-paclitaxel which leads to higher peri- and intratumoural enrichments. The continuing unchanged relevance of chemotherapy is often underestimated in the current discussions and will be comprehensively evaluated in this review.

\section{Zusammenfassung \\ $\nabla$}

Aufgrund der Erkenntnisse der modernen Molekularbiologie wird Brustkrebs heute als heterogene Erkrankung verstanden. Daraus ergibt sich das Ziel einer individualisierteren, mehr personalisierten Therapie. Hierfür sind schon eine Reihe von Zielmolekülen identifiziert worden. Mit der endokrinen Therapie von Patientinnen mit hormonrezeptorpositiven Tumoren wird der Grundsatz der zielgerichteten onkologischen Therapie bereits seit Jahrzehnten realisiert. Die moderne Therapie HER2-positiver Tumore ist ein weiteres Beispiel für die erfolgreiche Translation zielgerichteter Therapieprinzipien in den klinischen Alltag. Beim HER2-negativen metastasierten Mammakarzinom stehen Patientinnen in der klinischen Routine bisher mit Bevacizumab und Everolimus 2 zielgerichtete Medikamente zur Verfügung. Viele weitere neue Substanzen befinden sich noch in der klinischen Entwicklung. Es fehlen aber validierte prädiktive Marker zur Therapieentscheidung und -steuerung. Mit der Chemotherapie steht Patientinnen eine effektive palliative Therapie mit bewiesener Wirksamkeit zur Verfügung. Dabei wurden auch bei den Chemotherapeutika Ansätze für eine zielgerichtetere Therapie gegen Tumorzellen realisiert, so etwa mit der intrazellulären Aktivierung des Prodrugs Capecitabin oder mit dem aktiven albuminvermittelten Transports von nab-Paclitaxel, der zu einer höheren peri- und intratumoralen Anreicherung führt. Der unveränderte Stellenwert der Chemotherapie wird in den aktuellen Diskussionen jedoch häufig unterschätzt und soll in dieser Übersichtsarbeit umfassend beleuchtet werden. 


\section{Introduction}

\section{$\nabla$}

The advances in molecular biology have changed our opinions on an ideal oncological therapy. This is also true for breast cancer. The pioneering work of Perou and Sorlie on the intrinsic subtypes already published in 2000/2001 marks a turning point in our understanding of the disease $[1,2]$. Breast cancer is today considered to be a heterogeneous disease, the term is used as an umbrella for a multitude of molecularly defined tumour types. In addition, there is our knowledge of the intratumoural heterogeneity, since a tumour contains various molecular subpopulations including, most probably, also cells with stem cell properties $[3,4]$. Furthermore, the molecular properties of the primary tumour may differ from those of its metastases $[5,6]$. A further decisive factor in the development, maintenance and progression of malignant diseases is the interactions between tumour cells and their surroundings $[3,7]$.

Ideally, modern oncological therapies should be directed at specific molecular biological properties of the tumour disease (in the sense of a targeted therapy). This may involve either properties of the tumour cells or properties of the surrounding tissue or of the microenvironment. A glance at the lists of the European Medicines Agency EMA on submitted pharmaceutical approvals in the period 2012-2014 shows that, among the antineoplastic substances listed there, almost all are target directed, i.e., are drugs acting on specific cell components. However, requests for authorisation of targeted therapies or drugs for breast cancer at all are only rarely found in these lists [8].

A tumour exhibits two to eight gene mutations that are relevant for the development and maintenance of malignant growth and which can be assigned to 12 signal transduction pathways [9]. Hereby basic research has in the meantime identified a series of promising targets, also for breast cancer, as can be seen in $\square$ Table $\mathbf{1}$, however, due to the dynamics of basic research, this table does not claim to be complete. A detailed description of all target structures and processes is beyond the scope of this review. For more details we refer the reader to other review articles [3,911]. Our intention is to illustrate the position that chemotherapy still occupies in modern oncological therapy but without completely omitting a presentation of targeted therapies that are often the focal point of current discussions.

\section{Targeted Therapy for HER2-Positive Breast Cancer \\ $\nabla$}

The modern therapy for HER2-positive tumours is an impressive example for the successful translation of a targeted therapeutic principle into clinical routine. HER2 was initially identified as an unfavourable prognostic parameter, then as a target and finally as a predictive marker for an anti-HER2 therapy. The targeted therapy against HER2 results in a significantly prolonged survival for both early and advanced breast cancer and this is a significant clinical benefit for the patients [12-15]. The additional administration of the monoclonal antibody trastuzumab directed against HER2 to a first-line chemotherapy in combination with paclitaxel lengthens the median overall survival of patients with metastatic HER2-positive breast cancer from 18.4 to 22.1 months and in combination with docetaxel from 22.7 to 31.2 months $[16,17]$. In the second line after pre-treatment with trastuzumab and chemotherapy, the combination of the tyrosine kinase inhibitor lapatinib with capecitabine significantly improves the time to progression in comparison to capecitabine alone (hazard ratio
[HR] 0.57, p < 0.001) but does not show any difference in overall survival (HR $0.87, \mathrm{p}=0.206$ ). The median overall survival of patients in the combination arm amounted to 75 weeks (corresponding to about 16.7 months) $[18,19]$. Trastuzumab emtansine, an antibody-active substance conjugate of trastuzumab and the cytotoxin DM1, achieved for patients pre-treated with trastuzumab and taxane a significant prolongation of overall survival from 25.1 to 30.9 months in comparison to lapatinib and capecitabine [20]. In the meantime a median overall survival of 56.5 months has been realised with the first-line combination of docetaxel, trastuzumab and pertuzumab, a monoclonal antibody against HER2 and a HER2/HER3 dimerisation inhibitor [21]. Thus, due to the excellent results from the dual blockade alone, the necessity for chemotherapy was called into question and it was investigated whether the combination of two therapies targeted against HER2 offers an equivalent clinical benefit together with a better tolerability [22,23], as is being examined, for example, in the PERNETTA trial [24]. In the case of HER2-positive, hormone receptor-positive breast cancer, a "dual attack" with endocrine therapy and a targeted therapy against HER2 can be employed. Three trials have investigated the combination of trastuzumab or lapatinib with aromatase inhibitors [25-27]. In two studies an improvement of the progression-free survival in comparison to the aromatase inhibitor alone was demonstrated [26,27]. A benefit with regard to overall survival was not seen in any of the three trials [25-27].

\section{Targeted Therapy for HER2-Negative Breast Cancer $\nabla$}

For patients with HER2-negative metastatic breast cancer, besides the classical endocrine therapy for hormone receptor-positive disease, two targeted drugs are at present approved for use in clinical routine.

\section{Everolimus}

Everolimus is a selective inhibitor of the mammalian target of rapamycin (mTOR), a serine threonine kinase that participates in regulation of the cell cycle, angiogenesis and glycolysis, the activities of which are up-regulated in many human tumours $[28,29]$. In the BOLERO-2 trial, patients with hormone receptor-positive, advanced breast cancer who had experienced progression under a prior therapy with a non-steroidal aromatase inhibitor achieved a significant prolongation of progression-free survival (PFS) with a combination of everolimus and exemestane in comparison to exemestane alone (median PFS according to the evaluation of the study physician: 6.9 vs. 2.8 months, HR 0.43 , $\mathrm{p}<0.001$ ) [30]. This was not accompanied by a prolongation of overall survival (HR $0.89, p=0.14$ ) [31]. On the basis of the BOLERO-2 trial, everolimus in combination with exemestane was approved as therapy for hormone receptor-positive, HER2-negative, advanced breast cancer in postmenopausal women without symptomatic visceral metastases, when progression had occurred under treatment with a non-steroidal aromatase inhibitor [29].

\section{Bevacizumab}

Bevacizumab is a recombinant humanised monoclonal IgG-antibody against the vascular endothelial growth factor (VEGF) A. The docking of VEGF on the VEGF receptors of endothelial cells of blood vessels is prevented. In this way endothelial proliferation and angiogenesis are inhibited. Accordingly, the mechanism of 
Table 1 Survey of targeted, effective therapies undergoing clinical testing for metastatic breast cancer (modified from [3]).

\begin{tabular}{|c|c|c|}
\hline Site of action & Targeted structure/process & Drugs \\
\hline \multirow[t]{25}{*}{ Breast cancer cells } & human epidermal growth factor (HER) 2 receptor & anti-HER2 monoclonal antibodies \\
\hline & & HER2-tyrosine kinase inhibitor \\
\hline & & anti-HER2-antibody-active substance conjugate \\
\hline & poly-(ADP-ribose-)polymerase (PARP) & PARP inhibitors \\
\hline & $\begin{array}{l}\text { phosphoinositide 3-kinase (PI3K)/serine-threonine-kinase (AKT)/ } \\
\text { mammalian target of rapamycin (mTOR) signal pathway }\end{array}$ & mTORC1/2 inhibitors \\
\hline & & dual PI3K-mTOR inhibitors \\
\hline & & pan-PI3K inhibitors \\
\hline & & PI3Ka inhibitors \\
\hline & & PI3K $\beta$ inhibitors \\
\hline & & AKT inhibitors \\
\hline & insulin-like growth factor (IGF) and receptor (R) & IGF-1R inhibitors \\
\hline & & dual IGF-1R insulin receptor inhibitors \\
\hline & & anti-IGF monoclonal antibodies \\
\hline & fibroblast growth factor (FGF) & multi-targeted FGFR inhibitors \\
\hline & & highly selective FGFR inhibitors \\
\hline & methionine (MET) signal pathway & MET signal pathway inhibitors \\
\hline & cyclin-dependent kinases (CDK) & CDK inhibitors \\
\hline & mitogen-activated protein kinase (MAPK) signal pathway & MAPK signal pathway inhibitors \\
\hline & epigenetic regulation & histone deacetylation (HDAC) inhibitors \\
\hline & & histone methyltransferase (HMT) inhibitors \\
\hline & SRC protooncogene, non-receptor tyrosine protein kinase (SRC) & SRC inhibitors \\
\hline & human epidermal growth factor (HER) 3 receptor & HER3 inhibitors \\
\hline & aurora kinase inhibitors & aurora kinase inhibitors \\
\hline & androgen receptor & androgen receptor inhibitors \\
\hline & prolactin receptor & prolactin receptor inhibitor \\
\hline \multirow[t]{6}{*}{ Breast cancer stem cells } & notch signal pathway & $\mathrm{Y}$-secretase inhibitors \\
\hline & & delta-like ligand-4 inhibitors \\
\hline & hedgehog signal pathway & receptor-smoothened homologue (SMO) inhibitors \\
\hline & wingless-Int1 (WNT) signal pathway & frizzled receptor inhibitors \\
\hline & & $\beta$-catenin inhibitor \\
\hline & & porcupine inhibitor \\
\hline \multirow[t]{9}{*}{ Tumour microenvironment } & angiogenesis & anti-VEGF monoclonal antibodies \\
\hline & & tyrosine kinase inhibitor \\
\hline & programmed cell death protein (PD-1) and ligand (PD-L-1) & PD-1 inhibitors \\
\hline & & PD-L-1 inhibitors \\
\hline & lysis oxidase (LOX) & LOX inhibitors \\
\hline & chemokines and receptors & chemokine receptor inhibitor \\
\hline & integrins & integrin inhibitors \\
\hline & hypoxia & hypoxia-induced factor (HIF) $1 \alpha$ inhibitor \\
\hline & & hypoxia-activated prodrugs \\
\hline
\end{tabular}

action is assumed to involve a deficient supply of nutrients and oxygen to the tumour with a subsequent inhibition of growth $[32,33]$.

Data from three phase III trials on the first-line therapy for HER2negative breast cancer that have tested the additional administration of bevacizumab to chemotherapy are available. In all three studies a significant benefit in PFS was demonstrated for the therapy with bevacizumab: in the E2100 trial for the combination of bevacizumab with weekly paclitaxel compared with paclitaxel monotherapy (median PFS 11.8 vs. 5.9 months, HR 0.60, $\mathrm{p}<0.001$ ) [34], in the RIBBON-1 trial for the combination of bevacizumab and capecitabine vs. capecitabine (median PFS 8.6 vs. 5.7 months, HR 0.69, p < 0.001) and for bevacizumab in combination with taxane or anthracycline vs. only chemotherapy (median PFS 9.2 vs. 8.0 months, HR 0.64, p<0.001) [35] as well as in the AVADO trial for the combination of bevacizumab with docetaxel vs. docetaxel alone (median PFS 10.0 vs. 8.1 months, HR 0.67, $\mathrm{p}<0.001$ ) [36]. In none of the three studies did the significant PFS prolongation translate into an advantage with respect to sur- vival. A meta-analysis of all three studies confirmed the PFS benefit (HR 0.70, 95\% CI 0.57-0.86), but could not identify any advantage in overall survival for the combination of bevacizumab with chemotherapy as compared to chemotherapy alone (HR 0.95, 95\% CI 0.85-1.06) [37]. In the phase III TURANDOT trial in the first line, the combination of paclitaxel and bevacizumab was tested against the combination of capecitabine and bevacizumab. The required non-inferiority of capecitabine and bevacizumab for the primary end point PFS was not achieved in the planned interim analysis. The PFS for the combination of paclitaxel and bevacizumab amounted to 11.0 months and that for capecitabine with bevacizumab to 8.1 months; simultaneously the total response rate of $44 \%$ for the taxane-containing combination was significantly higher than that of $27 \%$ for the capecitabine-containing combination [38].

Also in the second line, the additional administration of bevacizumab to chemotherapy achieved a significant improvement in PFS (median PFS 7.2 vs. 5.1 months, HR 0.78, $\mathrm{p}=0.0072$ ) but no 
improvement in overall survival when compared to chemotherapy alone [39].

In November 2011 the American FDA withdrew the approval provisionally granted in 2008 for bevacizumab as treatment for metastatic breast cancer [40]. According to estimations of the European Medicines Agency, there is in the first line a positive benefit-risk balance. Therefore bevacizumab in combination with paclitaxel or capecitabine is approved in the EU for the first-line treatment of patients with metastatic breast cancer [33].

Finally, it should be noted that the above-reported results were all obtained in unselected patient populations since there are as yet no established predictive markers for a response to bevacizumab. It is possible that patients with higher VEGFR-2 or VEGF-A plasma levels benefit more from therapy with bevacizumab [41, 42]. A further possibility could be circulating endothelial cells [43]. However, prospective evidence is still lacking.

For patients with early breast cancer, the combination of bevacizumab with adjuvant chemotherapy did not show an advantage in invasive event-free survival or in overall survival in two large randomised trials $[41,44]$.

\section{Deficits in the Targeted Therapy for HER2-Negative Metastatic Breast Cancer \\ $\nabla$}

In the SAFIR01 trial between June 2011 and July 2012, 423 patients with metastatic breast cancer and a maximum of two previous chemotherapies were enrolled and the genomic profiles of their metastatic tissue were determined. In 48 of 407 patients with evaluable biopsy samples, targeted therapy could be initiated on the basis of the detection of specific genomic changes. 16 different regimes were employed. 28 patients were treated in the framework of phase I or phase II trials. For 43 patients it was possible to evaluate the response to therapy, 4 showed a partial response and 9 exhibited stable disease over $>16$ weeks [45]. This study exemplarily illustrates the problems which a personalised therapy has to face today. The feasibility of taking biopsies from metastases was an enrollment and thus a selection criterion. For these patients it was possible to obtain a comprehensive individual profile of at least the biopsied metastatic tissue. However, only for a small portion of these patients it was possible to initiate a targeted therapy based on the results of this analysis. The efficacy of this targeted therapy selected with the help of the most up to date methods was circumscribed, referred to the initially enrolled 423 patients, the rate of clinical benefits (partial remission or stable disease for $>16$ weeks) amounted to $3 \%$. Just the validation of the necessary predictive biomarkers in prospective studies represents an enormous challenge.

\section{Chemotherapy for Metastatic Breast Cancer \\ $\nabla$}

Chemotherapy targets rapidly proliferating cells and thus is rather an unspecific therapy. However, it remains an indispensable pillar of therapy for the treatment of patients with metastatic breast cancer, especially those with HER2-negative disease. At this point a short summary is called for on what we know and what we can expect from chemotherapy for HER2-negative breast cancer. The summary is limited to a presentation of results from randomised studies and meta-analyses.

Chemotherapy for HER2-negative breast cancer is indicated for hormone-receptor negative, i.e., triple-negative, disease or when for hormone receptor-positive patients an endocrine therapy is not possible, e.g., in the case of acute life-threatening disease or in cases with endocrine resistance. Even though a polychemotherapy leads to a better response and a longer progression-free survival compared with a monochemotherapy, it is however associated with a higher rate of toxicity [46-48]. Polychemotherapy should thus only be used in cases with a high pressure for remission, i.e., in cases with pronounced symptoms or a rapid progression of disease. The highest remission rates were achieved with a taxane in combination with an anthracycline or antimetabolites. Otherwise the progression-guided sequential administration of different monochemotherapies should be preferred over polychemotherapy $[46,49]$.

In cases of hypercalcaemia, bone pain due to metastases, osteolytic metastases or manifest osteoporosis induced by the tumour therapy there is in addition an indication for osteoprotective therapy with a bisphosphonate or the RANKL inhibitor denosumab. In this way the occurrence of skeletal complications can be delayed [46,50-54]. With regard to the efficiency in preventing skeletal events, a large phase III trial revealed a significant advantage of denosumab as compared to zoledronate. Neither of the two substances led to an improvement in survival [54]. Both substances constitute valid therapeutic options with different side effect profiles.

In principle, a wide spectrum of cytostatic agents is available. The decision for a specific regime depends on the previous adjuvant and palliative treatments, the response to a neoadjuvant therapy, symptoms and aggressiveness of the disease as well as toxicity to be expected in combination with the patient's general condition, previous diseases, comorbidity and the patient's expectations [49]. Recommendations of the AGO on palliative chemotherapy for breast cancer provide a useful aid in this respect ( $\triangle$ Tables 2 to 4) [49]. Anthracyclines and taxanes are considered to be the most effective substances $[46,49]$. In a recent meta-analysis it was also shown that a longer duration of therapy is associated with a better overall survival for the patient [55]. Whether or not this applies to all subtypes such as, e.g., ER-positive diseases with the possibility for endocrine maintenance therapy or the HER2-positive subtype with the possibility for an anti-HER2 maintenance therapy is a still open question. Thus, in general and especially for the palliative situation, it holds that therapy should be continued for as long as the therapeutic index remains positive, i.e., the metastatic disease is kept under control by the therapy and at the same time the toxicity of the therapy does not severely impair the patient's quality of life.

\section{Anthracyclines}

Anthracyclines were originally isolated from bacteria or produced semi-synthetically, they are antibiotics with cytostatic activity. They lead to inhibition of DNA replication and transcription. The cell cycle is blocked, above all during the S-phase and mitosis, as a result of an inhibition of the topoisomerase II enzyme and an intercalation in DNA [56].

A Cochrane meta-analysis of 33 studies with 5284 randomised patients showed a significant advantage of antibiotics-based anti-tumour regime with regard to the time to progression as compared to regimes without antibiotics (HR 0.84, 95\% CI 0.770.91 ) and tumour response (odds ratio [OR] 1.34, 95\% CI 1.211.48). This was also true when only the 29 trials with anthracycline-based regimes were considered [57].

In phase III trials for doxorubicin, first-line remission rates of $36 \%$, median time to therapy failure of 5.8 months, median pro- 
Table 2 AGO recommendations on palliative chemotherapy for HER2-negative, HR-positive MBC, first-line treatment.

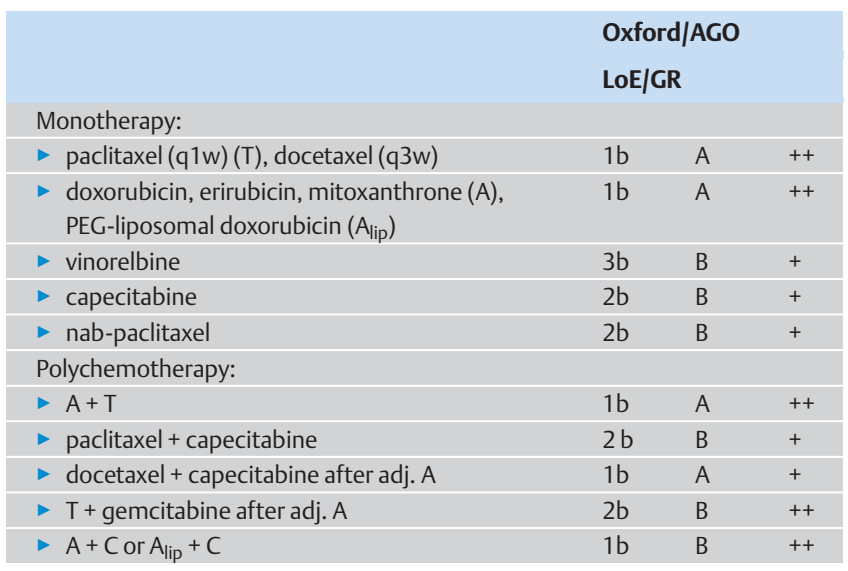

AGO: Arbeitsgemeinschaft Gynäkologische Onkologie (working group for gynaecological oncology); HR: hormone receptor; MBC: metastatic breast cancer [49].

Table 3 AGO recommendations on palliative chemotherapy for HER2-negative, HR-positive MBC after a previous anthracycline treatment.

\begin{tabular}{llll} 
& \multicolumn{3}{l}{ Oxford/AGO } \\
& LoE/GR & \\
- paclitaxel q1w & $1 \mathrm{a}$ & $\mathrm{A}$ & ++ \\
\hline - docetaxel q3w & $1 \mathrm{a}$ & $\mathrm{A}$ & ++ \\
\hline - capecitabine & 2b & $\mathrm{B}$ & ++ \\
- nab-paclitaxel & 2b & $\mathrm{B}$ & ++ \\
- PEG-liposomal doxorubicin & 2b & $\mathrm{B}$ & + \\
- eribulin & $1 \mathrm{~b}$ & $\mathrm{~B}$ & + \\
- vinorelbine & 2b & $\mathrm{B}$ & + \\
- docetaxel + PEG-liposomal doxorubicin & $1 \mathrm{~b}$ & $\mathrm{~B}$ & \pm
\end{tabular}

AGO: Arbeitsgemeinschaft Gynäkologische Onkologie (working group for gynaecological oncology); HR: hormone receptor; MBC: metastatic breast cancer [49].

Table 4 AGO recommendations on palliative chemotherapy for HER2-negative, HR-positive MBC after previous treatment with taxanes and anthracyclines.

\begin{tabular}{llll} 
& \multicolumn{3}{l}{ Oxford/AGO } \\
& LoE/GR & \\
& & & \\
- experimental therapies in trials & 2b & B & ++ \\
- eribulin & b & B & ++ \\
- vinorelbine & 2b & B & ++ \\
- (PEG-)liposomal doxorubicin & 2b & B & + \\
- gemcitabine + cisplatin/carboplatin & 2b & B & \pm \\
- gemcitabine + capecitabine & 2b & B & \pm \\
- gemcitabine + vinorelbine* & 1b & B & -
\end{tabular}

* NB: neutropenia/therapeutic index!

AGO: Arbeitsgemeinschaft Gynäkologische Onkologie (working group for gynaecological oncology); HR: hormone receptor; MBC: metastatic breast cancer [49]. gression-free survival of 7.8 months and median time for overall survival (OS) of 18.9, 20 and 22 months were reported [58-60]. Alopecia, mucositis, haematological toxicity (neutropenia, thrombocytopenia, anaemia) and cardiotoxicity are typical severe side effects of anthracyclines [52,53]. For liposomal formulations of doxorubicin similar efficacy data with reduced cardiotoxicity have been published [59-61].

\section{Taxanes}

Taxanes are cytostatic agents that occur in nature in certain types of yew tree and are now prepared semi-synthetically. Their mechanism of action is based on an attack on the cytoskeleton. They lead to an enhanced polymerisation of microtubules and then prevent disaggregation of the spindle apparatus through binding to a tubulin subunit. Thus the cell cycle is blocked in the G2 phase or, respectively, the M phase $[62,63]$.

\section{Taxanes vs. anthracyclines}

Several studies have compared the efficacy of anthracyclines and taxanes in metastatic breast cancer. A meta-analysis of 11 randomised trials that compared first-line taxanes in mono- or combination therapies with anthracycline-based therapy displayed a mixed picture. Therapy with taxanes exhibited a significantly reduced progression-free survival compared with anthracycline monotherapy (HR 1.19, $\mathrm{p}=0.011$ ), but no significant differences with regard to response rate ( $38 \mathrm{vs.} 33 \%, \mathrm{p}=0.08$ ) and overall survival (HR 1.01, $\mathrm{p}=0.90)$. Taxane-based combinations achieved significantly better results for response rate (57 vs. $46 \%$, $\mathrm{p}<0.001$ ) and progression-free survival (HR 0.92, $\mathrm{p}=0.031$ ), but not overall survival (HR 0.95, $\mathrm{p}=0.24$ ). On the whole, the median overall survival for all 3953 patients under anthracycline- or taxane-based therapies amounted to 19.3 months in the first line [64].

A meta-analysis from the Cochrane Institute of 21 trials with altogether 3643 patients suffering from metastatic breast cancer revealed significant advantages with regard to overall survival (HR 0.93, p = 0.05), time to progression (HR 0.92, p = 0.02) and response rate (OR 1.34, $\mathrm{p}<0.00001$ ) for the taxane-based regime compared to regimes without a taxane. This was not the case for a comparison between taxane monotherapy vs. anthracycline monotherapy, which demonstrated comparable efficacies in three trials $[65,66]$.

\section{Taxanes after anthracycline pre-treatment}

After anthracycline pre-treatment a median overall survival of up to 15.4 months was achieved with docetaxel. In a direct comparison this was significantly lower with paclitaxel, namely 12.7 months $(p=0.03)$ [67]. However, this was valid for a once every three weeks dosage which was later proved to be significantly inferior to a once weekly scheme in a phase III trial on patients with metastatic breast cancer with regard to response rate ( 29 vs. $42 \%$, $\mathrm{p}=0.0004)$, time to progression (HR 1.43, p < 0.0001) and overall survival (HR 1.28, p = 0.0092) [68].

\section{Docetaxel vs. paclitaxel}

A meta-analysis of 7 trials involving 1694 patients with metastatic breast cancer that directly compared the two taxanes paclitaxel and docetaxel with each other showed comparable efficacies with regard to overall response rates (RR 1.01, 95\% CI 0.88-1.15, $\mathrm{p}=0.92$ ), time to progression (HR 1.13, 95\% CI 0.81-1.58, $\mathrm{p}=0.46$ ), progression-free survival (HR 0.76, 95\% CI 0.58-1.00, $\mathrm{p}=0.052$ ), and overall survival (HR 0.87, 95\% CI 0.60-1.27, 
$\mathrm{p}=0.48$ ) albeit with different toxicity profiles [64]. Typical severe side effects of both taxanes were alopecia, stomatitis, haematological toxicity with febrile neutropenia as well as peripheral polyneuropathy $[62,63,69]$. In this context the incidence of severe peripheral polyneuropathy was significantly higher under the once weekly dosage of paclitaxel when compared to the once every three weeks dosage [68].

\section{nab-Paclitaxel}

nab-Paclitaxel, available in USA since 2005 and in Europe since 2008 , is a further taxane for the treatment of patients with breast cancer. As opposed to the other conventional taxanes paclitaxel and docetaxel, nab-paclitaxel does not need a solubilising agent and thus also no pre-medication as prophylaxis against severe hypersensitivity reactions [70]. Albumin serves as a physiological carrier molecule in the body for hydrophobic substances. nabPaclitaxel is a suspension of nanoparticles from human serum albumin to which the paclitaxel molecules are bound. A peri- and intratumoural enrichment of the active substance is achieved by means of an improved active transport via vascular endothelium by active receptor-mediated transcytosis [70-72]. There is as yet no confirmation from prospective data for the role attributed to the albumin-binding protein SPARC as a predictive biomarker in the therapy with nab-paclitaxel for metastatic breast cancer [73]. In three randomised studies nab-paclitaxel was compared with conventional taxanes. In a phase III trial nab-paclitaxel administered once every three weeks to patients with metastatic breast cancer, in comparison to conventional solvent-based paclitaxel administered once every three weeks, exhibited a significantly higher overall response rate (33 vs. 19\%, $\mathrm{p}=0.001$ ) and a significant prolongation of the time to disease progression (median TTP 23.0 vs. 16.9 weeks, HR $0.75, \mathrm{p}=0.006$ ). $42 \%$ of the patients were treated first line. A significant survival benefit of therapy with nab-paclitaxel was not seen for the entire collective but was observed for patients from the second line onwards (median OS 56.4 vs. 46.7 weeks, HR $0.73, p=0.024$ ) [74]. In the phase III GeparSepto trial 12 weekly doses of nab-paclitaxel $\left(125 \mathrm{mg} / \mathrm{m}^{2}\right)$ or conventional paclitaxel $\left(80 \mathrm{mg} / \mathrm{m}^{2}\right)$ were compared, both followed by 4 cycles of epirubicin and cyclophosphamide, as neoadjuvant therapy in patients with early breast cancer. Under neoadjuvant nab-paclitaxel the pathological complete remission rate (pCR) compared to conventional solvent-based paclitaxel could be increased significantly (pCR 38 vs. $29 \%$, odds ratio 1.53 , $\mathrm{p}<0.001$ ) [75].

One once every three weeks and two once weekly regimes with nab-paclitaxel were compared in a randomised phase II study with docetaxel in a once every three weeks dosage as first-line therapy for patients with metastatic breast cancer. Here nab-paclitaxel in the once weekly dose of $150 \mathrm{mg} / \mathrm{m}^{2}$ in comparison with docetaxel achieved a significant prolongation of the median progression-free survival (assessed by independent radiologists, median PFS 12.9 vs. 7.5 months, HR 0.495, p=0.0065) [76]. In the final analysis of overall survival the median overall survival with nab-paclitaxel in the once weekly dose of $150 \mathrm{mg} / \mathrm{m}^{2}$ amounted to 33.8 months, that with nab-paclitaxel in the once weekly dose of $100 \mathrm{mg} / \mathrm{m}^{2}$ to 22.2 months, to 27.7 months for nab-paclitaxel in the once every three weeks dose of $300 \mathrm{mg} / \mathrm{m}^{2}$ and to 26.6 months for the once every three weeks dose of $100 \mathrm{mg} / \mathrm{m}^{2}$ docetaxel. Merely the difference between nab-paclitaxel $150 \mathrm{mg} / \mathrm{m}^{2}$ vs. nab-paclitaxel $100 \mathrm{mg} / \mathrm{m}^{2}$ reached statistical significance (HR $0.575, p=0.008$ ) [77]. The toxicity profile of nab-paclitaxel differed from those of the conventional taxanes. Third and fourth degree neutropenias occurred significantly less often under nab-paclitaxel [62,64]. With nab-paclitaxel patients developed a peripheral sensory neuropathy more often than those under conventional paclitaxel administered once every three weeks, however this regressed more rapidly in the former patients. Thus, the median time to improvement of 2 nd degree disease and less was 22 days under nab-Paclitaxel compared to 79 days under solventbased paclitaxel [74].

\section{Vinorelbine}

The vinca alkaloid vinorelbine is also a spindle inhibitor. In contrast to the taxanes it inhibits the polymerisation of tubulin and so blocks mitosis in the G2-M phase [78].

After pre-treatment with anthracycline a vinorelbine monotherapy in contrast to monotherapy with melphalan achieves significant improvements with regard to time to progression and time to therapy failure (both 12 vs. 8 weeks, $\mathrm{p}<0.001$ ) as well as overall survival ( 35 vs. 31 weeks, $p=0.034$ ) [79]. Patients who received vinorelbine as a monotherapy after pre-treatment with anthracycline and taxane (15\% as first line, $54 \%$ as second line, and $31 \%$ as third line) achieved an overall response rate of $26 \%$, a median PFS of 4 months and a median OS of 16.4 months [80]. In the first line the additional administration of vinorelbine to epirubicin therapy resulted in a significant lengthening of the PFS compared to epirubicin monotherapy (median PFS 10.1 vs. 8.2 months, $\mathrm{p}=0.019$ ). However, there was neither a significant improvement in overall response rate ( 50 vs. $42 \%, \mathrm{p}=0.15$ ) nor in overall survival (median OS 19.1 vs. 18.0 months, $\mathrm{p}=0.50$ ) [81].

Neutropenia and anaemia are the typical severe side effects of vinorelbine [78-80].

\section{Capecitabine}

Capecitabine is a cytostatic agent from the group of antimetabolites. It is a prodrug that is transformed in the cell to the actual active substance, 5-fluorouracil (5-FU). 5-FU possesses a structural similarity with uracil and is incorporated into the RNA in place of uracil. In addition, it inhibits thymidylate synthetase, a key enzyme of pyrimidine synthesis that occurs both in healthy tissue and in higher concentrations in tumour tissue. Capecitabine thus leads to an inhibition of cell growth especially in cells with higher replication rates [82].

After anthracycline pre-treatment the combination of docetaxel and capecitabine in comparison to monotherapy with docetaxel achieves significant improvements in overall response rate (42 vs. $30 \%, p=0.006$ ), prolongation of the time to progression (median TTP 6.1 vs. 4.2 months, HR 0.652, p = 0.0001) and overall survival (median OS 14.5 vs. 11.5 months, HR 0.775, p=0.0126) [83]. After therapy with anthracycline and taxane monotherapy with capecitabine results in an overall response rate of up to $24.3 \%$, a median PFS of up to 5.2 months and a median OS of 22.4 months [84].

Typical severe side effects of capecitabine are stomatitis, diarrhoea and hand-foot syndrome [82-84].

\section{Eribulin}

Since 2011 eribulin has been available for the treatment of patients with local advanced or metastatic breast cancer after pretreatment with anthracycline and taxane and since 2014 for progression after at least one palliative chemotherapy line [85]. Eribulin belongs to the class of halichondrines that has been isolated from a marine sponge. It realises its antineoplastic activity in the 
same way as the taxanes and the vinca alkaloids by way of attack at the spindle apparatus of the cells. Eribulin inhibits the growth of microtubules but does not inhibit their polymerisation. Nonfunctional tubulin aggregates are formed. The cell cycle is blocked in the G2-M phase $[85,86]$.

For patients with metastatic breast cancer and pre-treatment with two to five chemotherapeutic regimes including one with an anthracycline and one with a taxane, a monotherapy with eribulin in comparison with the therapy of choice of the testing physician (up to $96 \%$ a chemotherapy) achieved a significant improvement in overall survival (median OS 13.1 vs. 10.6 months, HR 0.81, p = 0.041) [87].

In a randomised comparison with capecitabine monotherapy for patients with local advanced or metastatic breast cancer and previous treatments with anthracyclines and taxanes, eribulin therapy did not demonstrate a significant difference in progressionfree survival (median PFS 4.1 vs. 4.2 months, HR 1.079, p = 0.305) or in overall survival (median OS 15.9 vs. 14.5 months, HR 0.879 , $\mathrm{p}=0.056$ ) [83]. In the trials neutropenia, fatigue and peripheral neuropathy constituted the typical side effects $[85,87,88]$.

\section{Platinum salts}

The platinum salts cisplatin and carboplatin act via an interlinking of DNA single and double strands [89]. A specific status has been postulated for them in the therapy for patients with triplenegative and BRCA-positive breast cancer. In the CALGB 40603 phase III trial involving patients with triple-negative early breast cancer, the additional administration of carboplatin to taxaneand anthracycline-based neoadjuvant chemotherapy resulted in a significant increase in the pCR rate (pCR in breast and axilla [54 vs. $41 \%, p=0.0029$ ]) [90]. This had also been shown in the GeparSixto randomised phase II trial whereby the additional administration of carboplatin to a taxane- and anthracycline-based neoadjuvant chemotherapy led to a significant increase in the pCR rate for patients with triple-negative breast cancer (53.2 vs. $36.9 \%, p=0.005)$. In a retrospective subgroup analysis, the benefit from the additional administration of carboplatin was most apparent for patients with a BRCA mutation or a family history thereof $[91,92]$.

In the British TNT phase III trial involving patients with metastatic triple-negative or BRCA1/2-positive breast cancer, a monochemotherapy with carboplatin (AUC6 q3w) was compared with a monochemotherapy of docetaxel $\left(100 \mathrm{mg} / \mathrm{m}^{2} \mathrm{q} 3 \mathrm{w}\right)$. Here in the entire population of triple-negative patients carboplatin was not superior to docetaxel. In a small subgroup of 43 patients with proven BRCA1/2 mutations, on the other hand, a significantly higher overall response rate was seen for therapy with carboplatin in comparison to that with docetaxel (ORR 68.0 vs. $33.3 \%$, $\mathrm{p}=0.03)[93]$.

\section{Conclusions}

Our knowledge about breast cancer has increased at a rapid pace. Accordingly the opportunities for more intelligent, more individualised therapies have grown too.

However, for patients with HER2-negative metastatic breast cancer, a molecular biological, personalised therapy is still not a clinical reality. Most of the candidate drugs still have a long way to go before they can be approved. In the final analysis the relevant targets can be assigned to 12 signal transduction pathways [9]. Even today, and this is also true for the two already available drugs, there are (still) no validated predictive markers on the basis of which one can deduce a therapeutic response and thus selectively treat individual patients. Data from randomised trials that would be necessary for a prospective assessment are still lacking. After the disappointing results of the non-randomised preliminary trials, patients with HER2-negative, metastatic breast cancer received in one arm of the SAFIR02 trial targeted therapies according to individual genomic analyses and in the other arm maintenance chemotherapy [94].

However, in the light of the numerous targeted and effective therapies currently undergoing clinical development, the conventional practices for gaining scientific evidence must also be subject to scrutiny. Alternative concepts for intelligent approval studies need to be found. Also the call for biopsy samples of metastases is gaining in importance in combination with targeted therapies. In consideration of the evolution of the tumour genome, repeated rebiopsies and reanalyses appear to be meaningful prior to every new therapy line. A less invasive and more comprehensive alternative in future could be the sequencing of tumour DNA from plasma samples [95]. The creation of an effective and country-wide infrastructure to enable a rapid and reliable testing is one of the basic prerequisites for the successful integration of targeted therapies into clinical reality.

In spite of all the understandable enthusiasm for specific, targeted and effective therapies, it is often forgotten in the general discussion that for the patients chemotherapy still represents an effective, albeit unspecific, palliative therapy for which the efficacy has been unequivocally confirmed. In addition, options for a targeted therapy against tumour cells have also been realised with chemotherapeutic agents, examples for this include the intracellular activation of the prodrug capecitabine or the peri- and intratumoural enrichment of nab-paclitaxel on account of its improved, active albumin-mediated transport via vascular endothelium.

Finally, if we consider the targeted concepts for not only HER2positive but also for HER2-negative breast cancer more exactly, we can see that, alongside endocrine therapy, chemotherapy as a combination partner in targeted therapy continues to serve as the backbone not only for palliative but also for personalised systemic treatments. Chemotherapy is thus not an anachronism but rather is still an elemental building block in the systemic therapy for metastatic breast cancer.

\section{Disclosure \\ $\nabla$}

In the preparation of this manuscript the authors received editorial aid from Dr. Susanne Hell who was supported by an unrestricted grant from Celgene Germany. All statements in the article represent the opinions of all authors.

\section{Conflict of Interest}

The authors declare that, within the past three years, they have received support for the following activities: AS: consulting fees from Roche, Celgene, Eisai, Novartis; fees for lectures from Roche, Celgene, AstraZeneca, Amgen, GSK, Novartis. ER: fees for lectures from Amgen, AstraZeneca, Celgene, GSK, Janssen Cilag, Novartis, Pierre Fabre, Roche, Teva. JH: consulting fees from Roche, Novartis, Amgen, Eisei, GSK; fees for lectures from Roche, Novartis, Celgene, AstraZeneca. 


\section{References}

1 Perou CM, Sørlie T, Eisen MB et al. Molecular portraits of human breast tumours. Nature 2000; 406: 747-752

2 Sørlie T, Perou CM, Tibshirani R et al. Gene expression patterns of breast carcinomas distinguish tumor subclasses with clinical implications. Proc Natl Acad Sci U S A 2001; 98: 10869-10874

3 Zardavas D, Baselga J, Piccart M. Emerging targeted agents in metastatic breast cancer. Nat Rev Clin Oncol 2013; 10: 191-210

4 Yates LR, Campbell PJ. Evolution of the cancer genome. Nat Rev Genet 2012; 13: 795-806

5 de Dueñas EM, Hernández AL, Zotano AG et al. Prospective evaluation of the conversion rate in the receptor status between primary breast cancer and metastasis: results from the GEICAM 2009-03 ConvertHER study. Breast Cancer Res Treat 2014; 143: 507-515

6 Hoefnagel LD, van de Vijver MJ, van Slooten HJ et al. Receptor conversion in distant breast cancer metastases. Breast Cancer Res 2010; 12: R75

7 Hanahan D, Coussens LM. Accessories to the crime: functions of cells recruited to the tumor microenvironment. Cancer Cell 2012; 21: 309322

8 EMA. Medicines under evaluation. Online: http://www.ema.europa. eu/ema/index.jsp?curl=pages/medicines/document_listing/document _listing_000349.jsp\&mid=WC0b01ac05805083eb; last access: 01.12.2014

9 Vogelstein B, Papadopoulos N, Velculescu VE et al. Cancer genome landscapes. Science 2013; 339: 1546-1558

10 Arteaga CL, Sliwkowski MX, Osborne CK et al. Treatment of HER2-positive breast cancer: current status and future perspectives. Nat Rev Clin Oncol 2011; 9: 16-32

11 Rios J, Puhalla S. PARP inhibitors in breast cancer: BRCA and beyond. Oncology (Williston Park) 2011; 25: 1014-1025

12 Dahabreh IJ, Linardou H, Siannis F et al. Trastuzumab in the adjuvant treatment of early-stage breast cancer: a systematic review and metaanalysis of randomized controlled trials. Oncologist 2008; 13: 620-630

13 Viani GA, Afonso SL, Stefano EJ et al. Adjuvant trastuzumab in the treatment of her-2-positive early breast cancer: a meta-analysis of published randomized trials. BMC Cancer 2007; 7: 153

14 Valachis A, Mauri D, Polyzos NP et al. Trastuzumab combined to neoadjuvant chemotherapy in patients with HER2-positive breast cancer: a systematic review and meta-analysis. Breast 2011; 20: 485-490

15 Harris CA, Ward RL, Dobbins TA et al. The efficacy of HER2-targeted agents in metastatic breast cancer: a meta-analysis. Ann Oncol 2011; 22: $1308-1317$

16 Slamon DJ, Leyland-Jones B, Shak $S$ et al. Use of chemotherapy plus a monoclonal antibody against HER2 for metastatic breast cancer that overexpresses HER2. N Engl J Med 2001; 344: 783-792

17 Marty M, Cognetti F, Maraninchi D et al. Randomized phase II trial of the efficacy and safety of trastuzumab combined with docetaxel in patients with human epidermal growth factor receptor 2 positive metastatic breast cancer administered as first-line treatment: the M77001 Study Group. J Clin Oncol 2005; 23: 4265-4274

18 Geyer CE, Forster J, Lindquist $D$ et al. Lapatinib plus capecitabine for HER2-positive advanced breast cancer. N Engl J Med 2006; 355: 2733-2743

19 Cameron D, Casey M, Oliva C et al. Lapatinib plus capecitabine in women with HER-2-positive advanced breast cancer: final survival analysis of a phase III randomized trial. Oncologist 2010; 15: 924-934

20 Verma S, Miles D, Gianni L et al. Trastuzumab emtansine for HER2-positive advanced breast cancer. N Engl J Med 2012; 367: 1783-1791

21 Swain S, Kim S, Cortes J et al. Final overall survival (OS) analysis from the CLEOPATRA study of first-line $(1 \mathrm{~L})$ pertuzumab (Ptz), trastuzumab (T), and docetaxel (D) in patients (pts) with HER2-positive metastatic breast cancer (MBC). European Society for Medical Oncology 2014; Abstr. \#3500_PR

22 Blackwell KL, Burstein HJ, Storniolo AM et al. Overall survival benefit with lapatinib in combination with trastuzumab for patients with human epidermal growth factor receptor 2-positive metastatic breast cancer: final results from the EGF104900 Study. J Clin Oncol 2012; 30: 2585-2592

23 Gianni L, Pienkowski T, Im YH et al. Efficacy and safety of neoadjuvant pertuzumab and trastuzumab in women with locally advanced, inflammatory, or early HER2-positive breast cancer (NeoSphere): a randomised multicentre, open-label, phase 2 trial. Lancet Oncol 2012; 13 : 25-32

24 Clinicaltrial.gov. Online: https://clinicaltrials.gov/ct2/show/NCT01835 236?term=pertuzumab+breast\&rank=25; last access: 15.01 .2015
25 Huober J, Fasching PA, Barsoum $M$ et al. Higher efficacy of letrozole in combination with trastuzumab compared to letrozole monotherapy as first-line treatment in patients with HER2-positive, hormone-receptor-positive metastatic breast cancer - results of the eLEcTRA trial. Breast 2012; 21: 27-33

26 Schwartzberg LS, Franco SX, Florance A et al. Lapatinib plus letrozole as first-line therapy for HER-2+ hormone receptor-positive metastatic breast cancer. Oncologist 2010; 15: 122-129

27 Kaufman B, Mackey JR, Clemens MR et al. Trastuzumab plus anastrozole versus anastrozole alone for the treatment of postmenopausal women with human epidermal growth factor receptor 2-positive, hormone receptor-positive metastatic breast cancer: results from the randomized phase III TAnDEM study. J Clin Oncol 2009; 27: 5529-5537

28 EMA EPAR Afinitor. Online: http://www.ema.europa.eu/ema/index. jsp?curl=pages/medicines/human/medicines/001038/human_med_ 000633.jsp\&mid=WC0b01ac058001d124; last access: 01.12.2014

29 Aktuelle Fachinformation Afinitor ${ }^{\circledR}$

30 Baselga J, Campone M, Piccart $M$ et al. Everolimus in postmenopausal hormone-receptor-positive advanced breast cancer. N Engl J Med 2012; 366: 520-529

31 Piccart M, Hortobagyi GN, Campone $M$ et al. Everolimus plus exemestane for hormone-receptor-positive, human epidermal growth factor receptor-2-negative advanced breast cancer: overall survival results from BOLERO-2. Ann Oncol 2014; 25: 2357-2362

32 EMA EPAR Avastin. Online: http://www.ema.europa.eu/docs/de_DE/ document_library/EPAR_-_Product_Information/human/000582/ WC500029271.pdf; last access: 01.12.2014

33 Aktuelle Fachinformation Avastin ${ }^{\circledR}$

34 Miller K, Wang M, Gralow J et al. Paclitaxel plus bevacizumab versus paclitaxel alone for metastatic breast cancer. N Engl J Med 2007; 357: 2666-2676

35 Robert NJ, Diéras V, Glaspy J et al. RIBBON-1: randomized, double-blind, placebo-controlled, phase III trial of chemotherapy with or without bevacizumab for first-line treatment of human epidermal growth factor receptor 2-negative, locally recurrent or metastatic breast cancer. J Clin Oncol 2011; 29: 1252-1260

36 Miles DW, Chan A, Dirix LY et al. Phase III study of bevacizumab plus docetaxel compared with placebo plus docetaxel for the first-line treatment of human epidermal growth factor receptor 2-negative metastatic breast cancer. J Clin Oncol 2010; 28: 3239-3247

37 Rossari JR, Metzger-Filho O, Paesmans $M$ et al. Bevacizumab and breast cancer: a meta-analysis of first-line phase III studies and a critical reappraisal of available evidence. J Oncol 2012; 2012: 417673

38 Lang I, Brodowicz T, Ryvo L et al. Bevacizumab plus paclitaxel versus bevacizumab plus capecitabine as first-line treatment for HER2-negative metastatic breast cancer: interim efficacy results of the randomised, open-label, non-inferiority, phase 3 TURANDOT trial. Lancet Oncol 2013; 14: 125-133

39 Brufsky AM, Hurvitz S, Perez E et al. RIBBON-2: a randomized, doubleblind, placebo-controlled, phase III trial evaluating the efficacy and safety of bevacizumab in combination with chemotherapy for secondline treatment of human epidermal growth factor receptor 2-negative metastatic breast cancer. J Clin Oncol 2011; 29: 4286-4293

40 Pressemitteilung der FDA vom 18. November 2011. Online: http:// www.fda.gov/NewsEvents/Newsroom/PressAnnouncements/ ucm279485.htm; last access: 01.12.2014

41 Cameron D, Brown J, Dent R. Adjuvant bevacizumab-containing therapy in triple-negative breast cancer (BEATRICE): primary results of a randomised, phase 3 trial. Lancet Oncol 2013; 14: 933-942

42 Gianni L, Romieu GH, Lichinitser M. AVEREL: a randomized phase III trial evaluating bevacizumab in combination with docetaxel and trastuzumab as first-line therapy for HER2-positive locally recurrent/metastatic breast cancer. J Clin Oncol 2013; 31: 1719-1725

43 Bidard FC, Mathiot C, Degeorges A et al. Clinical value of circulating endothelial cells and circulating tumor cells in metastatic breast cancer patients treated first line with bevacizumab and chemotherapy. Ann Oncol 2010; 21: 1765-1771

44 Miller K, O'Neill AM, Dang CT et al. Bevacizumab (Bv) in the adjuvant treatment of HER2-negative breast cancer: Final results from Eastern Cooperative Oncology Group E5103. J Clin Oncol 2014; 32: 5 s (Suppl.; Abstr. 500)

45 André F, Bachelot T, Commo F et al. Comparative genomic hybridisation array and DNA sequencing to direct treatment of metastatic breast cancer: a multicentre, prospective trial (SAFIR01/UNICANCER). Lancet Oncol 2014; 15: 267-274 
46 DKG. Interdisziplinäre S3-Leitlinie für die Diagnostik, Therapie und Nachsorge des Mammakarzinoms. Langversion 3.0, Aktualisierung 2012. Online: http://www.krebsgesellschaft.de/download/S3

Brustkrebs_Update_2012_OL_Langversion.pdf; last access: 01.12.2014

47 Carrick S, Parker S, Wilcken $N$ et al. Single agent versus combination chemotherapy for metastatic breast cancer. Cochrane Database Syst Rev 2005; 2: CD003372

48 Carrick S, Parker S, Thornton CE et al. Single agent versus combination chemotherapy for metastatic breast cancer. Cochrane Database Syst Rev 2009; 2: CD003372

49 AGO. Diagnostik und Therapie primärer und metastasierter Mammakarzinome: Version 2015. 1D [online] 03.2015. Online: http://www. ago-online.de/de/fuer-mediziner/leitlinienempfehlungen/mamma/; last access: 20.04.2015

50 O'Rourke N, McCloskey E, Houghton F et al. Double-blind, placebo-controlled, dose-response trial of oral clodronate in patients with bone metastases. J Clin Oncol 1995; 13: 929-934

51 Conte PF, Latreille J, Mauriac L et al. Delay in progression of bone metastases in breast cancer patients treated with intravenous pamidronate: results from a multinational randomized controlled trial. The Aredia Multinational Cooperative Group. J Clin Oncol 1996; 14: 2552-2559

52 Theriault RL, Lipton A, Hortobagyi GN et al. Pamidronate reduces skeletal morbidity in women with advanced breast cancer and lytic bone lesions: a randomized, placebo-controlled trial. Protocol 18 Aredia Breast Cancer Study Group. J Clin Oncol 1999; 17: 846-854

53 Rosen LS, Gordon D, Kaminski M et al. Zoledronic acid versus pamidronate in the treatment of skeletal metastases in patients with breast cancer or osteolytic lesions of multiple myeloma: a phase III, doubleblind, comparative trial. Cancer J 2001; 7: 377-387

54 Stopeck AT, Lipton A, Body JJ et al. Denosumab compared with zoledronic acid for the treatment of bone metastases in patients with advanced breast cancer: a randomized, double-blind study. J Clin Oncol 2010; 28: 5132-5139

55 Gennari A, Stockler M, Puntoni M et al. Duration of chemotherapy for metastatic breast cancer: a systematic review and meta-analysis of randomized clinical trials. J Clin Oncol 2011; 29: 2144-2149

56 EMA EPAR Caelyx. Online: http://www.ema.europa.eu/ema/index.jsp? curl=pages/medicines/human/medicines/000089/human_med_ 000683.jsp\&mid=WC0b01ac058001d124; last access: 01.12.2014

57 Lord S, Ghersi D, Gattellari $M$ et al. Antitumour antibiotic containing regimens for metastatic breast cancer. Cochrane Database Syst Rev 2004; 4: CD003367

58 Sledge GW, Neuberg D, Bernardo P et al. Phase III trial of doxorubicin, paclitaxel, and the combination of doxorubicin and paclitaxel as front-line chemotherapy for metastatic breast cancer: an intergroup trial (E1193). J Clin Oncol 2003; 21: 588-592

59 Harris L, Batist G, Belt R et al. Liposome-encapsulated doxorubicin compared with conventional doxorubicin in a randomized multicenter trial as first-line therapy of metastatic breast carcinoma. Cancer 2002; 94: $25-36$

60 O'Brien MER, Wigler N, Inbar M et al. Reduced cardiotoxicity and comparable efficacy in a phase III trial of pegylated liposomal doxorubicin $\mathrm{HCl}\left(\right.$ CAELYX $^{\mathrm{TM}} /$ Doxil $\left.^{\circledR}\right)$ versus conventional doxorubicin for first-line treatment of metastatic breast cancer. Ann Oncol 2004; 15: 440-449

61 Batist G, Harris L, Azarnia $N$ et al. Improved anti-tumor response rate with decreased cardiotoxicity of non-pegylated liposomal doxorubicin compared with conventional doxorubicin in first-line treatment of metastatic breast cancer in patients who had received prior adjuvant doxorubicin: results of a retrospective analysis. Anticancer Drugs 2006; 17: 587-595

62 Aktuelle Fachinformation Taxotere ${ }^{\circledR}$

63 Aktuelle Fachinformation Paclitaxel Hexal ${ }^{\circledR}$

64 Piccart-Gebhart MJ, Burzykowski T, Buyse M et al. Taxanes alone or in combination with anthracyclines as first-line therapy of patients with metastatic breast cancer. J Clin Oncol 2008; 26: 1980-1986

65 Ghersi D, Wilcken N, Simes J et al. Taxane containing regimens for metastatic breast cancer. Cochrane Database Syst Rev 2005; 2: CD003366

66 Ghersi D, Wilcken N, Simes RJ. A systematic review of taxane-containing regimens for metastatic breast cancer. Br J Cancer 2005; 93: 293-301

67 Jones SE, Erban J, Overmoyer B et al. Randomized phase III study of docetaxel compared with paclitaxel in metastatic breast cancer. J Clin Oncol 2005; 23: 5542-5551
68 Seidman A, Berry D, Cirrincione C et al. Randomized phase III trial of weekly compared with every-3-weeks paclitaxel for metastatic breast cancer, with trastuzumab for all HER-2 overexpressors and random assignment to trastuzumab or not in HER-2 nonoverexpressors: final results of cancer and leukemia group B protocol 9840. J Clin Oncol 2008; 26: $1642-1649$

69 Qi WX, Shen Z, Lin F et al. Paclitaxel-based versus docetaxel-based regimens in metastatic breast cancer: a systematic review and meta-analysis of randomized controlled trials. Curr Med Res Opin 2013; 29: 117125

70 Aktuelle Fachinformation Abraxane ${ }^{\circledR}$

71 Desai $N$. Nab technology: a drug delivery platform utilising endothelial gp60 receptor-based transport and tumour-derived SPARC for targeting. Drug Delivery Report. 16th ed. 2007/2008: 37-41

72 Desai $N$, Trieu $V$, Yao $Z$ et al. Increased antitumor activity, intratumor paclitaxel concentrations, and endothelial cell transport of cremophor-free, albumin-bound paclitaxel, ABI-007, compared with cremophor-based paclitaxel. Clin Cancer Res 2006; 12: 1317

73 Schneeweiss A, Seitz J, Smetanay K et al. Efficacy of nab-paclitaxel does not seem to be associated with SPARC expression in metastatic breast cancer. Anticancer Res 2014; 34: 6609-6615

74 Gradishar W, Tjulandin S, Davidson $N$ et al. Phase III trial of nanoparticle albumin-bound paclitaxel compared with polyethylated castor oilbased paclitaxel in women with breast cancer. J Clin Oncol 2005; 23 : 7794-7803

75 Untch M, Jackisch C, Schneeweiss A et al. A randomized phase III trial comparing neoadjuvant chemotherapy with weekly nanoparticlebased paclitaxel with solvent-based paclitaxel followed by anthracycline/cyclophosphamide for patients with early breast cancer (GeparSepto); GBG 69. SABCS 2014; Abstr. S2-07

76 Gradishar W, Krasnojon D, Cheporov $S$ et al. Significantly longer progression-free survival with nab-paclitaxel compared with docetaxel as first line therapy for metastatic breast cancer. J Clin Oncol 2009; 27: 3611-3619

77 Gradishar WJ, Krasnojon D, Cheporov S et al. Phase-II trial of nab-paclitaxel compared with docetaxel as first-line chemotherapy in patients with metastatic breast cancer: final analysis of overall survival. Clin Breast Cancer 2012; 12: 313-321

78 Aktuelle Fachinformation Navelbine ${ }^{\circledR}$

79 Jones S, Winer E, Vogel C. Randomized comparison of vinorelbine and melphalan in anthracycline-refractory advanced breast cancer. J Clin Oncol 1995; 13: 2567-2574

80 Martin M, Ruiz A, Munoz M et al. Gemcitabine plus vinorelbine versus vinorelbine monotherapy in patients with metastatic breast cancer previously treated with anthracyclines and taxanes: final results of the phase III Spanish Breast Cancer Research Group (GEICAM) trial. Lancet Oncol 2007; 8: 219-225

81 Eijlertsen B, Mouridsen HT, Langkjer S et al. Phase III study of intravenous vinorelbine in combination with epirubicin versus epirubicin alone in patients with advanced breast cancer: a Scandinavian Breast Group trial (SBG9403). J Clin Oncol 2004; 22: 2313-2320

82 Aktuelle Fachinformation Xeloda ${ }^{\circledR}$

83 O'Shaughnessy J, Miles D, Vukelja S et al. Superior survival with capecitabine plus docetaxel combination therapy in anthracycline-pretreated patients with advanced breast cancer: phase III trial results. J Clin Oncol 2002; 20: 2812-2823

84 Pallis AG, Boukovinas I, Ardavanis A et al. A multicenter randomized phase III trial of vinorelbine/gemcitabine doublet versus capecitabine monotherapy in anthracycline- and taxane-pretreated women with metastatic breast cancer. Ann Oncol 2012; 23: 1164-1169

85 Aktuelle Fachinformation Halaven ${ }^{\circledR}$

86 Jordan MA, Kamath K, Manna T et al. The primary antimitotic mechanism of action of the synthetic halichondrin E7389 is suppression of microtubule growth. Mol Cancer Ther 2005; 4: 1086-1095

87 Cortes J, O'Shaughnessy J, Loesch $D$ et al. Eribulin monotherapy versus treatment of physician's choice in patients with metastatic breast cancer (EMBRACE): a phase 3 open-label randomised study. The Lancet 2011; 377: 914-923

88 Kaufman PA, Awada A, Twelves C et al. A phase III, open-label, randomized, multicenter study of eribulin mesylate versus capecitabine in patients with locally advanced or metastatic breast cancer previously treated with anthracyclines and taxanes. SABCS 2012; Abstr. S6-6

89 Aktuelle Fachinformation Axicarb ${ }^{\circledR}$ 
90 Sikov WM, Berry DA, Perou CM et al. Impact of the addition of carboplatin and/or Bevacizumab to neoadjuvant once-per-week paclitaxel followed by dose-dense doxorubicin and cyclophosphamide on pathologic complete response rates in stage II to III triple-negative breast cancer: CALGB 40603 (Alliance). J Clin Oncol 2015; 33: 13-21

91 von Minckwitz G, Schneeweiss A, Salat C et al. A randomized phase II trial investigating the addition of carboplatin to neoadjuvant therapy for triple-negative and HER2-positive early breast cancer (GeparSixto). J Clin Oncol 2013; 31 (Suppl.; Abstr. 1004)
92 von Minckwitz G, Schneeweiss A, Loibl S et al. Neoadjuvant carboplatin in patients with triple-negative and HER2-positive early breast cancer (GeparSixto; GBG 66): a randomised phase 2 trial. Lancet Oncol 2014; 15: 747-756

93 Tutt A, Ellis P, Kilburn L et al. The TNT trial: A randomized phase III trial of carboplatin (C) compared with docetaxel (D) for patients with metastatic or recurrent locally advanced triple negative or BRCA $1 / 2$ breast cancer (CRUK/07/012). SABCS 2014; Abstr. S3-01

94 Clinicaltrial.gov. Online: https://clinicaltrials.gov/ct2/show/record/ NCT02299999?term=safir+02\&rank=2; last access: 20.04 .2015

95 Murtaza M, Dawson SJ, Tsui DW et al. Non-invasive analysis of acquired resistance to cancer therapy by sequencing of plasma DNA. Nature 2013; 497: 108-112 